\title{
Reversible cerebral vasoconstriction syndrome in a patient taking citalopram and Hydroxycut: a case report
}

\author{
Gregory L Cvetanovich ${ }^{1 *}$, Pankajavalli Ramakrishnan ${ }^{1,2}$, Joshua P Klein ${ }^{1}$, Vikram R Rao ${ }^{1}$ and Allan H Ropper ${ }^{1}$
}

\begin{abstract}
Introduction: Reversible cerebral vasoconstriction syndrome presents with thunderclap headaches accompanied by mild neurologic deficits and is characterized by multifocal narrowing of the cerebral arteries that resolves over days to weeks. This syndrome may be idiopathic or occur in special contexts, most often involving adrenergic or serotonergic overactivity. To the best of our knowledge, reversible cerebral vasoconstriction syndrome has not previously been reported in association with Hydroxycut use in the literature.

Case Presentation: We report the case of a 65-year-old Caucasian woman on longstanding citalopram who developed reversible cerebral vasoconstriction syndrome two weeks after beginning to take the weight-loss supplement Hydroxycut.
\end{abstract}

Conclusion: There are sparse data about the safety of herbal supplements such as Hydroxycut, even though the Food and Drug Administration has banned some herbal ingredients, such as ephedra, that were in this preparation in the past. This case highlights the importance of considering herbal supplements and potential drug interactions in the genesis of otherwise unexplained reversible cerebral vasoconstriction syndrome.

\section{Introduction}

Reversible cerebral vasoconstriction syndrome (RCVS) is the term for a group of rare syndromes characterized by multifocal narrowing of the cerebral arteries that resolves over the course of days to weeks [1]. Patients present with sudden, severe "thunderclap" headaches that may be accompanied by neurologic deficits [1]. Clinical situations associated with the development of RCVS include pregnancy or the postpartum period and various medications and illicit drugs [2]. RCVS is diagnosed on the basis of this clinical presentation, exclusion of other causes of thunderclap headache such as subarachnoid hemorrhage and cerebral vasculitis by cerebrospinal fluid analysis, documentation of multifocal vasoconstriction of the cerebral arteries by angiography, and of reversibility of the vasoconstriction within 12 weeks of onset, although there may be permanent neurologic injury if stroke occurs secondary to vasospasm [1]. Treatment has included calcium

\footnotetext{
* Correspondence: Gregory_cvetanovich@hms.harvard.edu

'Department of Neurology, Brigham and Women's Hospital, 75 Francis

Street, Boston, MA 02115, USA

Full list of author information is available at the end of the article
}

channel blockers [3,4] or magnesium [5], and discontinuation of potential triggers for RCVS, particularly adrenergic or serotonergic compounds.

We report the case of a patient on longstanding citalopram who developed RCVS two weeks after beginning to take the weight-loss supplement Hydroxycut, and we review the literature identifying factors associated with development of RCVS.

\section{Case Presentation}

A 65-year-old Caucasian woman presented to her local hospital with sudden-onset, bifrontal, pounding headache described as "getting hit in the head with an axe." The headache was the worst of her life and did not improve after she took acetaminophen, caffeine, and butalbital. There was hyperacusis, photophobia and nausea. Noncontrast head computed tomography (CT) and brain magnetic resonance imaging (MRI) at the time of admission were normal and she was treated with prednisone for presumed intractable migraine. Aside from a similar but milder headache one week prior to her current presentation, she reported only a sparse past history of migraines that ceased

\section{Biomed Central}


after her hysterectomy and no family history of migraines or strokes. She had hyperlipidemia treated with simvastatin $40 \mathrm{mg}$ daily, lumbar spinal compression fractures, multiple miscarriages and depression that had been treated for several years with citalopram $20 \mathrm{mg}$ daily. On further questioning, our patient reported taking the weight-loss supplement Hydroxycut beginning two weeks prior to her thunderclap headache. On admission, her body mass index was 22.3, and she was normotensive on lisinopril $10 \mathrm{mg}$ daily. She had not previously been on lisinopril, which was presumably initiated at the outside hospital for prednisoneinduced hypertension. We held the lisinopril for the duration of her hospitalization given her normal to low blood pressures. Her fasting lipid panel revealed cholesterol 223 $\mathrm{mg} / \mathrm{dL}$, triglycerides $141 \mathrm{mg} / \mathrm{dL}$, high density lipoprotein $61 \mathrm{mg} / \mathrm{dL}$, low density lipoprotein $134 \mathrm{mg} / \mathrm{dL}$, very low density lipoprotein $28 \mathrm{mg} / \mathrm{dL}$ and lipoprotein(a) $6 \mathrm{mg} / \mathrm{dL}$.

Two days after admission, she developed bilateral leg weakness and left-sided visual disturbances that she described as "blank lines." A repeat MRI revealed areas of restricted diffusion consistent with acute infarcts in the bilateral anterior cerebral artery territories and in her right occipital lobe (Figure 1). The following investigations were unrevealing: hypercoagulability studies, rheumatic and vasculitic screening labs, magnetic resonance venography, transthoracic echocardiogram with bubble contrast, and Holter monitoring. LA lumbar puncture, performed while our patient was being treated with prednisone, revealed 0 white blood cells (WBC), 48 red blood cells (RBC), cerebrospinal fluid (CSF) protein $27 \mathrm{mg} / \mathrm{dL}$, glucose $81 \mathrm{mg} / \mathrm{dL}$ and no xanthochromia. CT angiography (CTA) was obtained, which revealed multifocal segmental cerebral artery vasoconstriction, most prominent in the bilateral anterior and posterior cerebral arteries (Figures 2A and 2B).

We made the diagnosis of RCVS and began treatment with nimodipine $30 \mathrm{mg}$ three times daily. Over the subsequent days, her headache resolved and her vision and leg weakness improved. Our patient's blood pressures at admission and prior to starting nimodipine were 92-

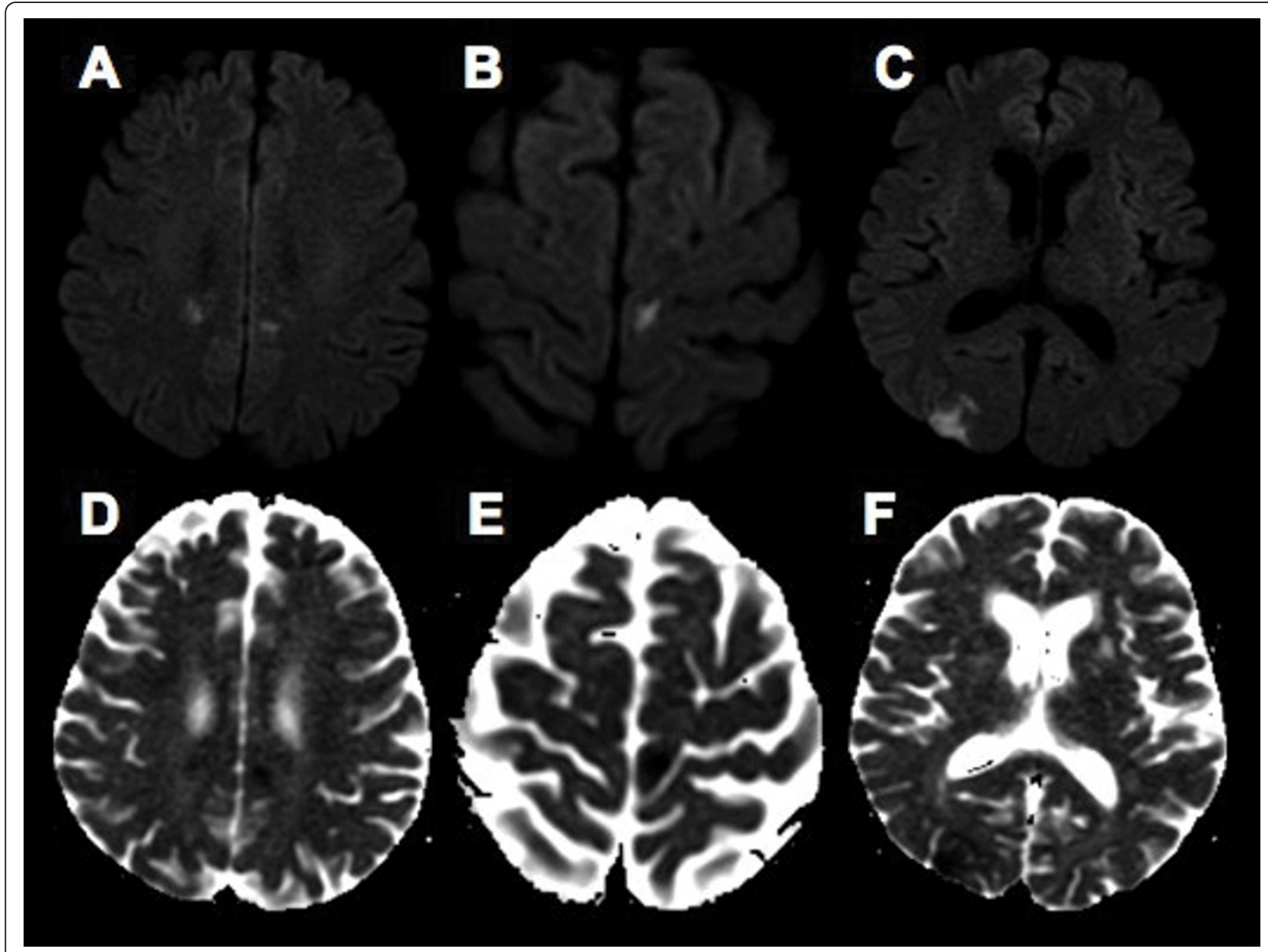

Figure 1 RVCS-related ischemic strokes. Diffusion-weighted MRI (A, B, C) and apparent diffusion coefficient maps (D, E, F) revealed lesions in the right occipital lobe and bilateral anterior cerebral artery territories consistent with ischemic strokes. 


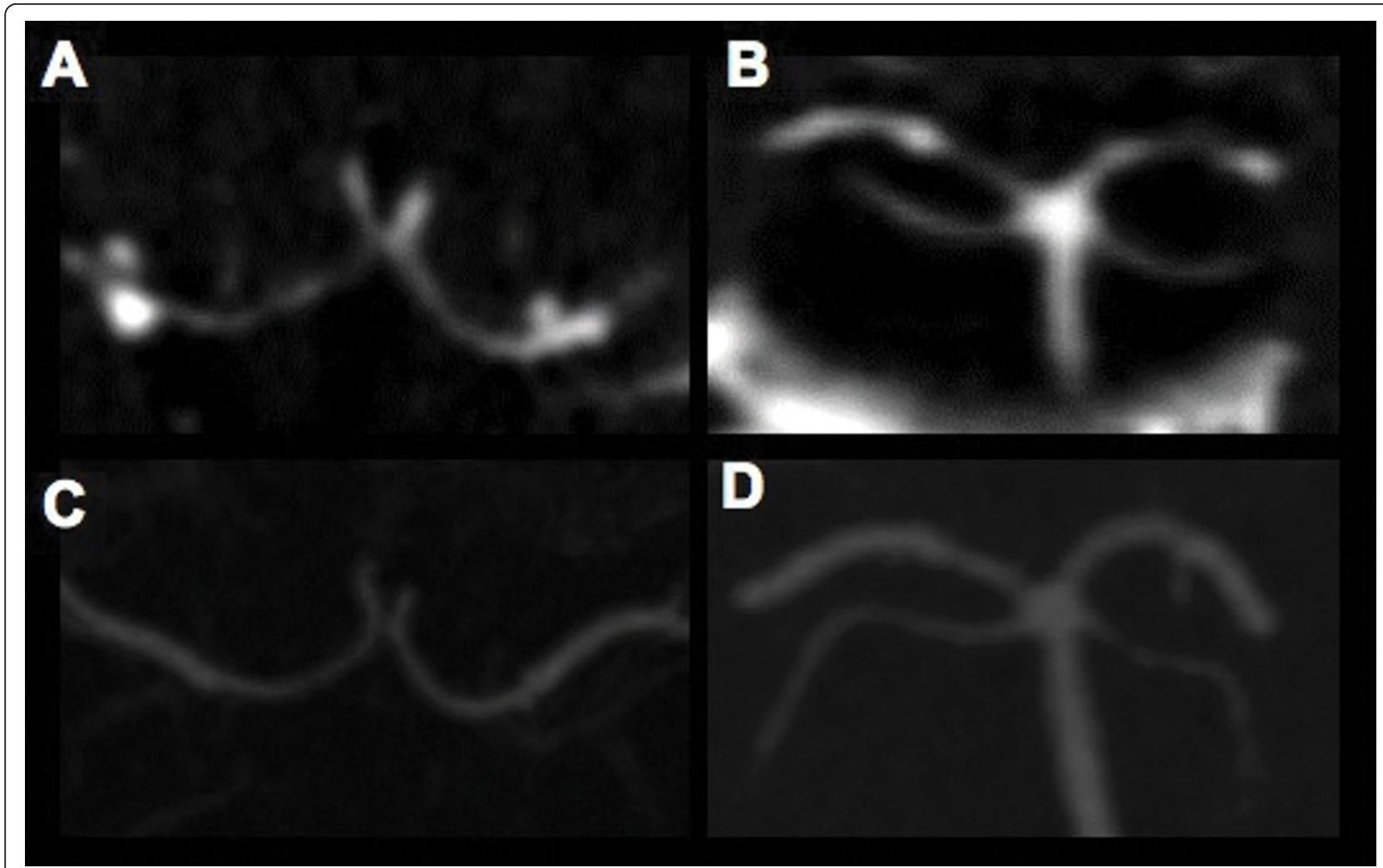

Figure 2 RCVS on computed tomography angiography. CTA obtained during hospitalization showed multifocal segmental vasoconstrictions most prominent in the bilateral anterior (A) and posterior (B) cerebral arteries. Follow-up CTA six weeks after discharge revealed marked resolution of cerebral artery vasoconstriction, shown here for anterior (C) and posterior (D) cerebral arteries.

116/54-58 mmHg on no antihypertensive medications. After beginning nimodipine for RCVS, her systolic blood pressures ranged from the high 80 s to low 100 s (mmHg). We administered intravenous fluid bolus as needed to keep her systolic blood pressure above 90 $\mathrm{mmHg}$, in an effort to balance maintaining adequate cerebral perfusion while continuing nimodipine treatment for RCVS. Our patient tolerated this well without any clinical decline or symptomatic hypotension.

She was discharged on nimodipine and advised not to take Hydroxycut and citalopram, which had been discontinued when a diagnosis of RCVS was first suspected. At the time of discharge, her systolic blood pressures remained in the $90 \mathrm{~s}$ to low $100 \mathrm{~s} \mathrm{mmHg}$. Therefore, she was advised to measure her blood pressure at home and take nimodipine only if systolic blood pressure was over $100 \mathrm{mmHg}$. Following discharge, our patient experienced no headaches and no recurrence of her presenting symptoms. At a follow-up appointment, she had no residual leg weakness and significant improvement of her left visual field deficit, although she reported that her vision had not returned to her baseline. CTA performed six weeks after discharge showed marked resolution of cerebral vasoconstriction, confirming the diagnosis of RCVS (Figures 2C and 2D).

\section{Discussion}

This case illustrates the cardinal features of RCVS: thunderclap headache, lack of subarachnoid hemorrhage by CSF and radiographic analysis, ostensible exclusion of cerebral vasculitis by CSF and systemic testing, and angiographic demonstration of multifocal segmental cerebral artery vasoconstriction that resolves with time or calcium channel blocker treatment. It also exemplifies ischemic strokes as complications of RCVS [6], emphasizing the delicate balance between maintenance of adequate cerebral perfusion pressure to avoid watershed infarcts while using calcium channel blockers to mitigate against worsening vasoconstriction [2].

The other aspect of RCVS treatment is identification and discontinuation of the potential triggers of RCVS. The clinical settings for RCVS include pregnancy and the postpartum state, serotonergic and sympathomimetic drugs and tumors, direct or neurosurgical trauma, hypertension, primary headache disorders such as migraine and other miscellaneous conditions such as 
hypercalcemia and porphyria [1,2]. Regardless of etiology, RCVS is thought to occur due to perturbation of cerebral vascular tone [1].

Although amphetamine-related weight-loss supplements and selective serotonin reuptake inhibitors including citalopram have been associated with RCVS [1,7-9], Hydroxycut has not previously been implicated. It is impossible to prove causality, but the temporal relationship between the patient's initiation of Hydroxycut and development of RCVS and the rapid reversal of symptoms and vasospasm following cessation implicate the supplement as a contributing cause in this case. Citalopram may have acted in concert with the newlyinitiated Hydroxycut to cause this patient's RCVS, though the fact that she tolerated citalopram well for several years before developing RCVS argues against the antidepressant drug as the sole trigger.

Hydroxycut is among the most popular weight-loss supplements with nine million units sold in 2008 in the US alone [10] and, like most herbal supplements, contains poorly characterized components whose side effect profiles are ill-defined [11]. After Hydroxycut was introduced in 2002, the first adverse events were probably related to its ephedra component, which was banned by the Food and Drug Administration (FDA) in 2004 for causing severe cardiovascular, central nervous system and hepatic toxicity [12]. Since the removal of ephedra from Hydroxycut in 2004, published adverse events have included numerous cases of hepatotoxicity [13], one case of rhabdomyolysis [14] and one case of hypertensive retinopathy [15]. In May 2009, the FDA warned the public about Hydroxycut hepatotoxicity, prompting the manufacturer to withdraw all Hydroxycut products [16].

Recently, a new Hydroxycut formulation has been introduced, and it is this one that our patient with RCVS was taking. Based on the tendency of sympathomimetic agents to trigger RCVS, caffeine may have been the ingredient responsible for RCVS as the usual daily dose of Hydroxycut contains $400 \mathrm{mg}$ of caffeine per day [17], which is equivalent to four cups of coffee. Caffeine is known to cause cerebral vasoconstriction [18], although it has not been associated with RCVS. Other components of the new Hydroxycut formulation may have contributed, although to our knowledge none has vasoconstrictive properties.

\section{Conclusion}

We report a case report of a patient on longstanding citalopram who developed RCVS two weeks after beginning to take the weight-loss supplement Hydroxycut. Given the sparse data about the efficacy and safety of herbal supplements such as Hydroxycut, it is advisable to consider the potential roles of dietary supplements and drug interactions in cases of otherwise unexplained cerebrovascular disease.

\section{Consent}

Written informed consent was obtained from the patient for publication of this case report and any accompanying images. A copy of the written consent is available for review by the Editor-in-Chief of this journal.

\section{Author details}

'Department of Neurology, Brigham and Women's Hospital, 75 Francis Street, Boston, MA 02115, USA. ${ }^{2}$ Department of Neurology, Critical Care Neurology, Massachusetts General Hospital, 55 Fruit Street, Boston, MA 02114, USA

\section{Authors' contributions}

GC drafted the manuscript. PR and JPK assisted with neuroradiology. All authors analyzed and interpreted patient data and read and approved the final manuscript.

\section{Competing interests}

The authors declare that they have no competing interests.

Received: 19 May 2011 Accepted: 10 November 2011

Published: 10 November 2011

\section{References}

1. Calabrese LH, Dodick DW, Schwedt TJ, Singhal AB: Narrative review: reversible cerebral vasoconstriction syndromes. Ann Intern Med 2007, 146(1):34-44.

2. Singhal $A B$, Bernstein RA: Postpartum angiopathy and other cerebral vasoconstriction syndromes. Neurocrit Care 2005, 3(1):91-97.

3. Lu SR, Liao YC, Fuh JL, Lirng JF, Wang SJ: Nimodipine for treatment of primary thunderclap headache. Neurology 2004, 62(8):1414-1416.

4. Dodick DW: Reversible segmental cerebral vasoconstriction (Call-Fleming syndrome): the role of calcium antagonists. Cephalalgia 2003, 23(3):163-165.

5. Singhal $A B$ : Postpartum angiopathy with reversible posterior leukoencephalopathy. Arch Neurol 2004, 61(3):411-416.

6. Hajj-Ali RA, Furlan A, Abou-Chebel A, Calabrese LH: Benign angiopathy of the central nervous system: cohort of 16 patients with clinical course and long-term followup. Arthritis Rheum 2002, 47(6):662-669.

7. Noskin O, Jafarimojarrad E, Libman RB, Nelson JL: Diffuse cerebral vasoconstriction (Call-Fleming syndrome) and stroke associated with antidepressants. Neurology 2006, 67(1):159-160.

8. Oz O, Demirkaya S, Bek S, Eroglu E, Ulas UH, Odabasi Z: Reversible cerebral vasoconstriction syndrome: case report. J Headache Pain 2009, 10(4):295-298.

9. Forman HP, Levin S, Stewart B, Patel M, Feinstein S: Cerebral vasculitis and hemorrhage in an adolescent taking diet pills containing phenylpropanolamine: case report and review of literature. Pediatrics 1989, 83(5):737-741.

10. FDA Warns Consumers to Stop Using Hydroxycut Products Risk of Liver Injury. [http://www.fda.gov/downloads/NewsEvents/PublicHealthFocus/ UCM155660.pdf].

11. Lobb A: Hepatoxicity associated with weight-loss supplements: a case for better post-marketing surveillance. World J Gastroenterol 2009, 15(14):1786-1787.

12. Sales of Supplements Containing Ephedrine Alkaloids (Ephedra) Prohibited. [http://web.archive.org/web/20080126150250/www.fda.gov/oc/ initiatives/ephedra/february2004/].

13. Fong TL, Klontz KC, Canas-Coto A, Casper SJ, Durazo FA, Davern TJ, Hayashi P, Lee WM, Seeff LB: Hepatotoxicity due to hydroxycut: a case series. Am J Gastroenterol 2010, 105(7):1561-1566.

14. Dehoney S, Wellein M: Rhabdomyolysis associated with the nutritional supplement Hydroxycut. Am J Health Syst Pharm 2009, 66(2):142-148. 
15. Willis SL, Moawad FJ, Hartzell JD, Iglesias M, Jackson WL: Hypertensive retinopathy associated with use of the ephedra-free weight-loss herbal supplement Hydroxycut. MedGenMed 2006, 8(3):82.

16. FDA Warning on Hydroxycut Products. [http://www.fda.gov/ ForConsumers/ConsumerUpdates/ucm152152.htm]

17. Hydroxycut ingredient list. [http://www.hydroxycutadvanced.com/].

18. Addicott MA, Yang LL, Peiffer AM, Burnett LR, Burdette JH, Chen MY,

Hayasaka S, Kraft RA, Maldjian JA, Laurienti PJ: The effect of daily caffeine use on cerebral blood flow: How much caffeine can we tolerate? Hum Brain Mapp 2009, 30(10):3102-3114.

doi:10.1186/1752-1947-5-548

Cite this article as: Cvetanovich et al: Reversible cerebral

vasoconstriction syndrome in a patient taking citalopram and

Hydroxycut: a case report. Journal of Medical Case Reports 2011 5:548.

Submit your next manuscript to BioMed Central and take full advantage of:

- Convenient online submission

- Thorough peer review

- No space constraints or color figure charges

- Immediate publication on acceptance

- Inclusion in PubMed, CAS, Scopus and Google Scholar

- Research which is freely available for redistribution

Submit your manuscript at www.biomedcentral.com/submit 